\title{
Benzodithiophene Fused Cyclopentannulated Aromatics via a Palladium-Catalyzed Cyclopentannulation and Scholl Cyclodehydrogenation Strategy
}

\author{
Waseem A. Hussain and Kyle N. Plunkett \\ Department of Chemistry and Biochemistry and the Materials Technology Center, Southern Illinois University, \\ Carbondale, IL 62901 United States
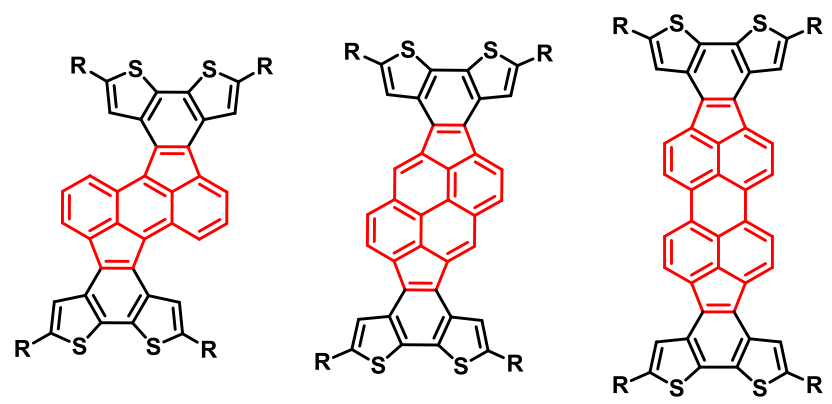

\begin{abstract}
:
We report the synthesis of a new class of cyclopenta-fused polyaromatic hydrocarbon (CP-PAH) incorporating fused benzodithiophene subunits. These CP-PAHs were prepared utilizing a twostep process involving a palladium catalyzed cyclopentannulation followed by a Scholl cyclodehydrogenation. This work broadens the scope of annulation chemistry by employing 1,2bis(5-hexylthiophen-3-yl)ethyne and dibromoaryl derivatives based on anthracene, pyrene and perylene to give 4,4',4",4'"-(cyclopenta[hi]aceanthrylene-1,2,6,7-tetrayl)tetrakis(2hexylthiophene) , 4,4',4",4"'-(dicyclopenta[cd,jk]pyrene-1,2,6,7-tetrayl)tetrakis(2-hexylthiophene) and 1,2,7,8-tetrakis(5-hexylthiophen-3-yl)-1,2,7,8-tetrahydrodicyclopenta[cd,lm]perylene. Scholl cyclodehydrogenation of the pendant thiophene units provided access to the $\pi$-extended polyaromatic $\quad$ 2,5,11,14-tetrahexylrubiceno[5,4-b:6,7-b':12,11-b":13,14b'"]tetrathiophene, 2,5,11,14-tetrahexyldithieno-[4,5:6,7]indeno[1,2,3cd]dithieno[4,5:6,7]indeno-[1,2,3-jk]pyrenes, $\quad$ and 2,9,12,19tetrahexyldithieno[4,5:6,7]indaceno[1,2,3-cd]dithieno[4,5:6,7]indaceno[1,2,3-lm]perylene that possess helicene-like fragments. The anthracene-based CP-PAH was contorted owing to [5]helicene-like arrangements while the pyrene and perylene-based systems were essentially planar. The fully conjugated small molecules give low optical gaps $(1.7-2.1 \mathrm{eV})$ with broad light absorption. The HOMO and LUMO energies of the CP-PAHs were found to be in the range of 5.48 to $-5.05 \mathrm{eV}$ and -3.48 to $-3.14 \mathrm{eV}$, respectively. Finally, the anthracene-based CP-PAH was found to be a p-type semiconductor when tested in an organic field effect transistor.
\end{abstract}




\section{Introduction:}

The rational design of pi-extended aromatics has been utilized to tune and improve optoelectronic properties such as broad light absorption, reduced optical gaps and greater charge carrier mobilities. However, one drawback of enlarging the aromatic surface of PAHs is reduced solubilities owing to significant pi-pi stacking. Contorted aromatic systems, typically based on helicene-like arrangements that provide congestion among closely spaced aromatic segments, have been understood as an important class of PAHs for several decades ${ }^{1-2}$ and offer solubility benefits in relation to similar sized flat aromatics. A re-emergence of their syntheses over the past decade has occurred owing to new synthetic methodologies as well as their applications in organic electronic devices. $^{3-18}$

Metal catalyzed cyclopentannulation chemistry provides a convenient method for accessing new PAH architectures. ${ }^{19-20}$ Recent advances in catalytic designs have broadened the scope of substrates suitable for annulation reactions. ${ }^{21-28}$ The cyclopentannulation chemistry provides a quick route for ring expansion in polyaromatic systems to generate non-alternant cyclopentannulated polycyclic aromatic hydrocarbons (CP-PAHs). The extended aromatic core provides modulation of absorption properties and larger surface areas for pi-stacking, which can sometimes lead to better charge transport. ${ }^{29-31}$ The five-member rings often enable anti-aromatic characteristics and low lying lowest unoccupied molecular orbitals (LUMOs).

In this work, we synthesized a new series of small molecule CPPAHs 1-3 with attached benzodithiophene subunits via palladium-catalyzed annulations and Scholl dehydrogenation reactions (Figure 1). This work is a further expansion of the small-molecule cyclopentannulation chemistry of Garcia-Garibay ${ }^{32-33}$ and Muellen, ${ }^{34}$ as well as our previous work involving phenanthrene subunits attached to cyclopentannulated anthracene and pyrene cores 4-5 (Figure 1). ${ }^{11,12}$ In addition, we recently demonstrated this annulation chemistry could be utilized to form conjugated ladder

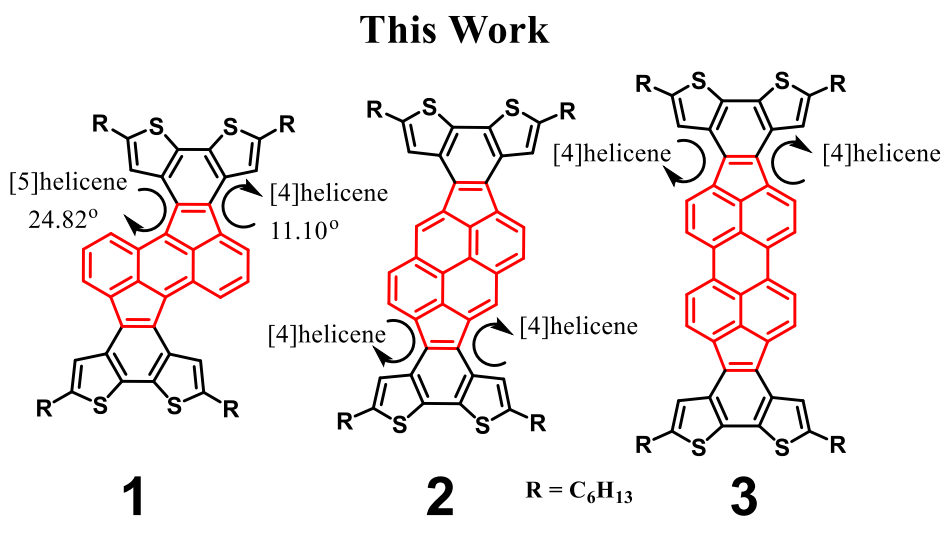

Previous Work

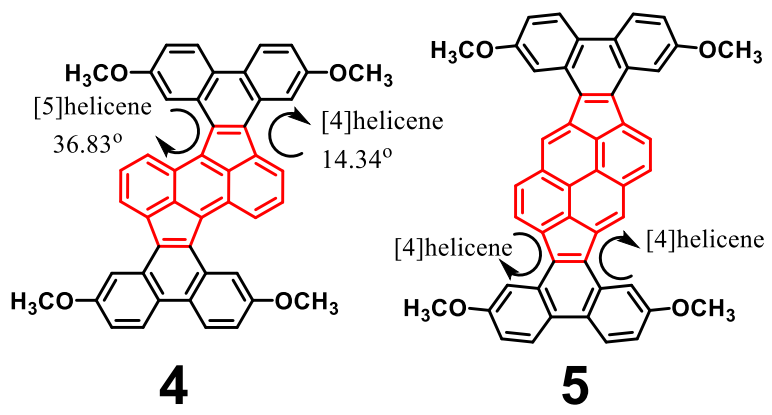

Figure 1. Newly synthesized class of contorted PAHs, with calculated splay angles on energy minimized TDDFT-B3LYP/6$311 \mathrm{~g}(\mathrm{~d}, \mathrm{p})$ structure. 
polymers with phenanthrene-like as well as benzothiophene-like subunits in the polymer backbone. ${ }^{35}$ While the inclusion of benzodithiophene appendages was successful in the polymer system, we had yet to systematically explore small molecule derivatives that incorporate the benzodithiophene substitution strategy. This work was important as the use of thiophene rich small molecules and polymers in semiconducting materials is ubiquitous. The condensed thiophene systems with alternating benzene and thiophene moieties have been studied for their semiconducting and rich excited state photophysical properties ${ }^{36}$ and thiophene rich heteroacenes are known for enhancement of intermolecular charge transfer through S-S interactions. ${ }^{37}$ This work focuses on probing the effects of the fused benzodithiophene units to the aromatic cores of cyclopentannulated anthracene, pyrene and perylene.

\section{Results and Discussions}

For the inclusion of thiophene appendages through the cyclopentannulation strategy, we employed 1,2-bis(5-hexylthiophen-3-yl)ethyne $\mathbf{1 0}$ as a reactant with dibromo-PAH derivatives based on anthracene 7 , pyrene 8 , and perylene 9 . The cyclopentannulation reaction was carried out utilizing our previously developed catalyst system comprising of $\mathrm{Pd}_{2}(\mathrm{dba})_{3}$ and $\mathrm{P}(\mathrm{o}-\mathrm{Tol})_{3}$ with $\mathrm{KOAc}$ as base and $\mathrm{LiCl}$ as additive with modified solvent composition. The best yields were achieved employing 1:1 solvent mixture of DMF:toluene and gave 11-13 in 40-80\% yield (Scheme 1). To complete the ring closing of the flanking thiophene rings to generate the benzodithiophene subunit, a Scholl cyclodehydrogenation with $\mathrm{FeCl}_{3}$ was utilized to give 1-3 in yields of 80-90\%.

This chemistry provides convenient access to expanded rubicene, ${ }^{38-40}$ indenopyrene, ${ }^{41-42}$ and indacenoperylene ${ }^{43-44}$ derivatives.

CP-PAHs 11-13 were highly soluble in halogenated and aromatic solvents, which can be attributed to the orthogonal arrangement of the appended thiophene groups to the core leading to the depression of $\pi-\pi$ stacking. However, after the Scholl cyclodehydrogenation the solubilities of products 1-3 were significantly altered. While $\mathbf{1}$ was still reasonably soluble, $\mathbf{2}$ and $\mathbf{3}$ were significantly less soluble in common organic solvents. The Density Functional Theory (DFT, B3LYP/6-311g $(\mathrm{d}, \mathrm{p})$ ) energy minimized structures of 1-3 and 11-13 gives clarification of the varying solubilities (ESI). For anthracene based 1, the arrangement of fused rings generates two [4] helicene and two [5] helicene like fragments (Figure 1). ${ }^{20}$ These two fragments give rise to two different splay angles that drive the aromatic system to contort out of planarity. ${ }^{4,20}$ Comparison to the previously prepared phenanthrene-based $\mathbf{4}$ shows the benzodithiophene analog $\mathbf{1}$ is less contorted, with the splay angles of the [5]helicene and [4] helicene subunits decreasing from $36.83^{\circ}$ to $24.82^{\circ}$ and $14.34^{\circ}$ to $11.10^{\circ}$, respectively. The reduction in splay angle can be attributed to the smaller size of the thiophene aromatic residue that has a smaller internal angle ${ }^{45}$ and therefore alleviates some of the close arrangement of the hydrogen atoms. In contrast, the DFT minimized structures of $\mathbf{2}$ and $\mathbf{3}$ show virtually flat arrangements of the benzodithiophene subunits in relation 
to the indeonopyrene and indacenoperylene cores (ESI). Here, the [4]helicene arrangement that includes both the five-membered hydrocarbon and thiophene rings do not lead to congestion in the coves. ${ }^{25,38,46-47}$ Therefore, the virtually flat geometries of $\mathbf{3}$ and $\mathbf{4}$ are more prone to significant aggregation and become considerably less soluble.

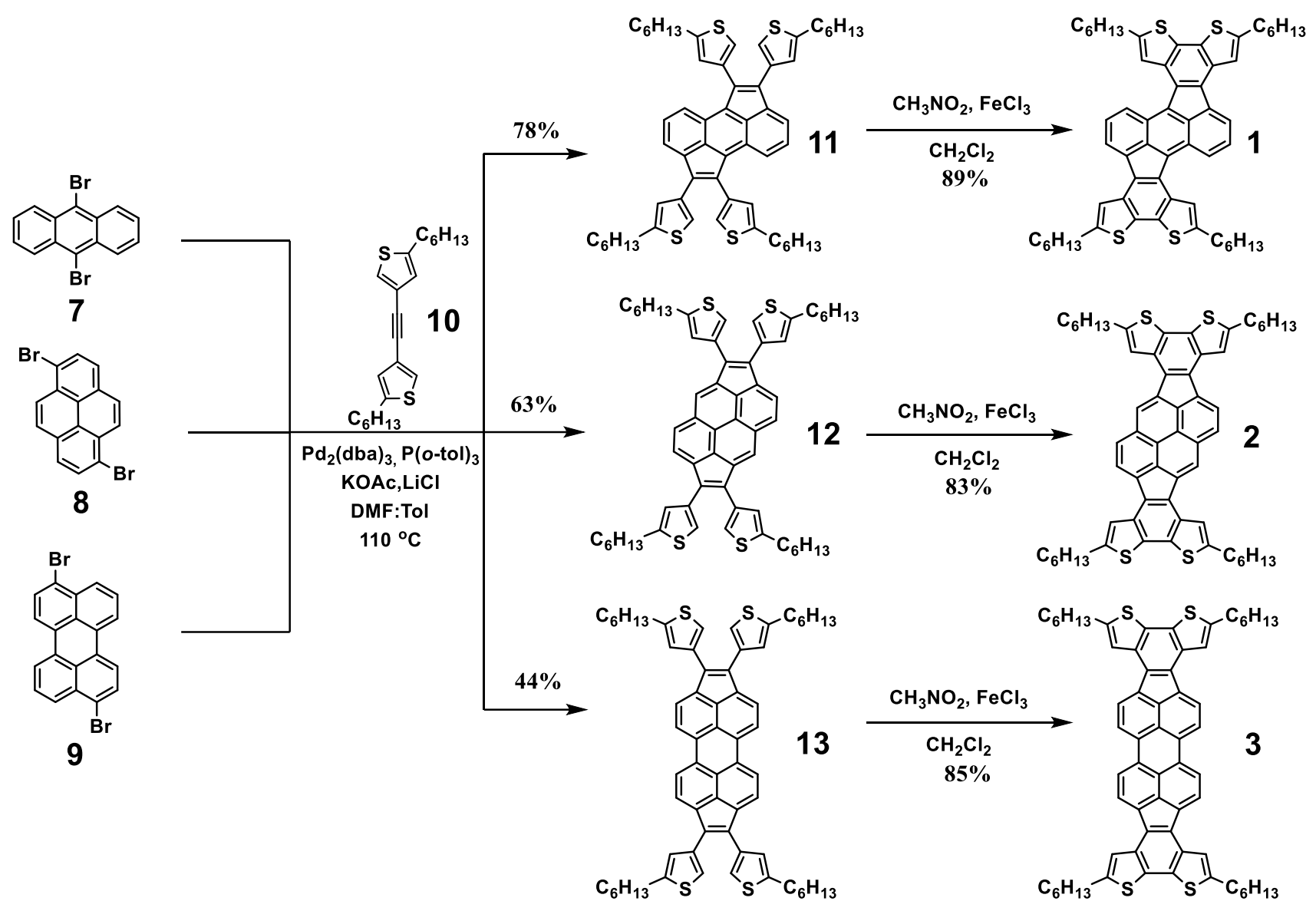

Scheme 1: Synthetic pathways for contorted molecules 1-3.

The absorption spectra of the new CP-PAHs show broad light absorption in the visible region of the light spectrum (Figures 2 and 3 ). In solution, a general trend of increasing $\lambda_{\text {max,onset }}$ is found for the initially prepared CP-PAHs going from pyrene (12) to perylene (13) to anthracene (11). Upon cyclodehydrogenation, there are slight modulations in spectral and electrochemical features, which are obvious in solution via color changes. The $\pi$-extended PAH 1 shows a significant hypsochromic shift $(\sim 100 \mathrm{~nm})$ of the longest wavelength absorbed compared to open ring 11. The hypsochromic shift is less pronounced in the perylene $\mathbf{3}(\sim 40 \mathrm{~nm})$ and pyrene $\mathbf{2}(\sim 10 \mathrm{~nm})$ based systems. Along with these changes in the longest wavelength absorptions, there are changes to the general peak shapes and intensities of other transitions for all PAH systems. Photooxidation of all compounds was carried out in chloroform solutions and monitored by UV-Vis spectroscopy 
(ESI). All compounds showed significant oxidation over the course of the solution-based experiments. Interestingly, anthracene based $\mathbf{1}$ was the most readily oxidized but its pre-cursor $\mathbf{1 1}$ was the most stable. For the other two PAH systems, the ring-closed forms were more readily oxidized. In contrast, the compounds are stable in their solid forms with minimal decomposition detected for extended times.

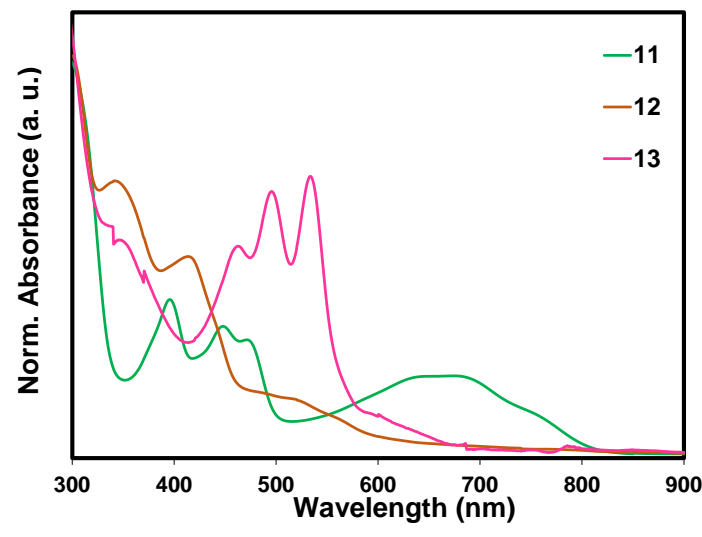

Figure 2. Solution state (normalized) absorption spectrum of 11-13 in $\mathrm{CHCl}_{3}$. Molar absorptivity in ESI.

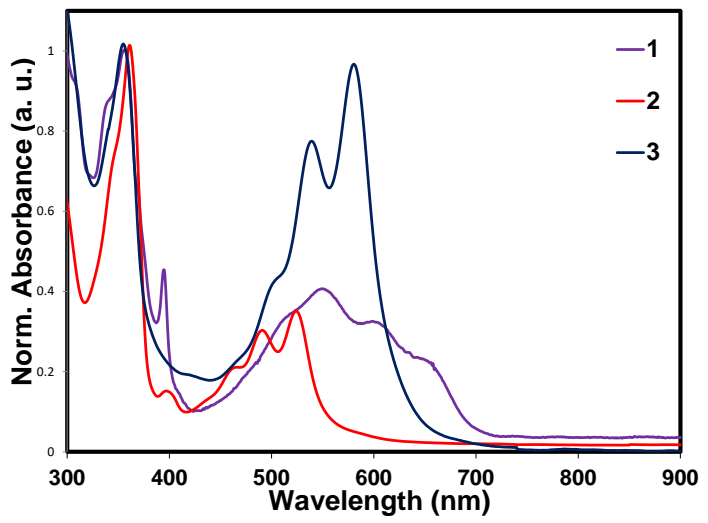

Figure 3. Solution state (normalized) absorption spectra of 1-3 in $\mathrm{CHCl}_{3}$. Molar absorptivity in ESI.

The electrochemical features of CP-PAHs 1-3 and 11-13 were investigated by cyclic voltammetry (Figure 4). Each of the cyclopentannulated compounds 11-13 gave two reversible reduction peaks. Pseudo-reversible oxidation was observed in 11 and $\mathbf{1 3}$ whereas, compound 12 gave an irreversible oxidation. The $\pi$-extended molecules 1-3 generally show two reversible reduction waves with the exception of $\mathbf{1}$ giving a pseudo-reversible reduction at the higher potential. An irreversible or quasi reversible oxidation is observed in $\mathbf{2}$ and $\mathbf{3}$ (ESI) while $\mathbf{1}$ gave a reversible oxidation. The overall presence of two reversible reduction waves at lower potentials in compounds $\mathbf{1 - 3}$ and their precursors 11-13 is owing to the ability to form cyclopentadienyl-like anions by accepting electrons to give $4 n+2$ aromatic systems.

The highest occupied molecular orbital (HOMO) and lowest unoccupied molecular orbital (LUMO) values were calculated using a

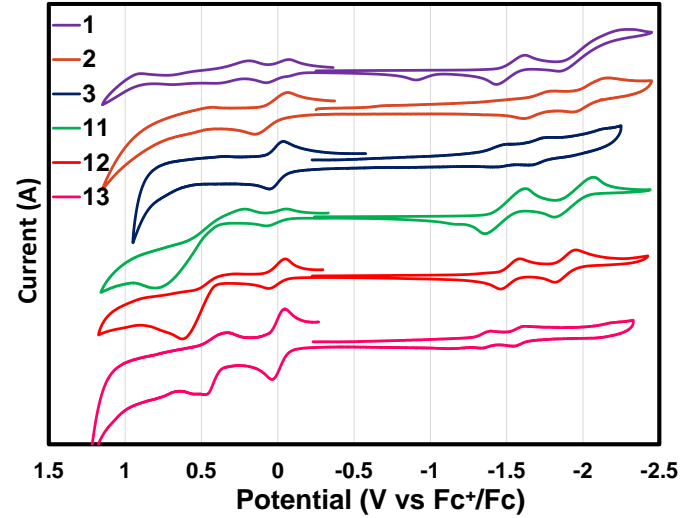

Figure 4: Cyclic voltammetry of 1-3 and 11-13 in 0.1 $\mathrm{M}$ tetrabutylammonium hexafluorophosphate in DCM with glassy carbon working electrode, platinum counter electrode, and $\mathrm{Ag} / \mathrm{AgCl}$ reference electrode. Scan rate $=50 \mathrm{mV} \mathrm{s}^{-1}$. Ferrocene added as an internal standard and reference to $0 \mathrm{~V}$. ferrocene standard (Table 1). The LUMO levels ranged from -3.14 to $-3.48 \mathrm{eV}$ while the $\mathrm{HOMO}$ levels ranged from -5.05 to $-5.48 \mathrm{eV}$. In comparison to phenanthrene based $4(\mathrm{HOMO}=-5.32 \mathrm{eV}, \mathrm{LUMO}=-3.56 \mathrm{eV})^{20}$, compound 1 
possessed higher HOMO (-5.05 eV) and LUMO (-3.33 eV) energy levels, as would be expected with the electron rich thiophene systems. The electronic structure and the HOMO / LUMO contours of compounds 1-3 and 11-13 were calculated using DFT with the basis set B3LYP/6$311 \mathrm{~g}(\mathrm{~d}, \mathrm{p})$ and can be found in Figure 5. There exist some variations among the HOMOs and LUMOs of ring open and closed CP-PAHs. The HOMOs of $\mathbf{1}$ and $\mathbf{1 1}$ depict a high electron density

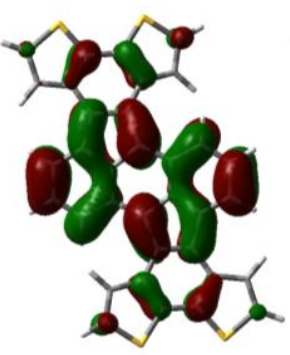

$\mathbf{1}(-2.9708 \mathrm{eV})$

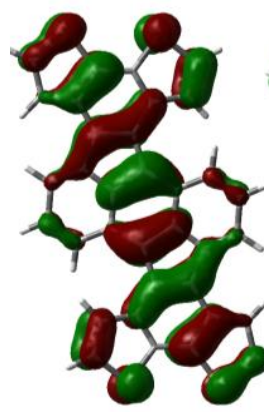

$\mathbf{1}(-5.3916 \mathrm{eV})$

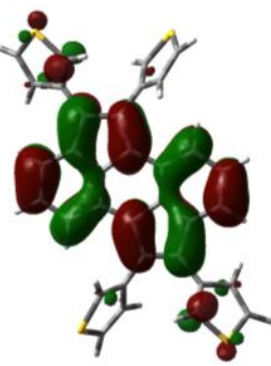

11(-3.0237 eV)

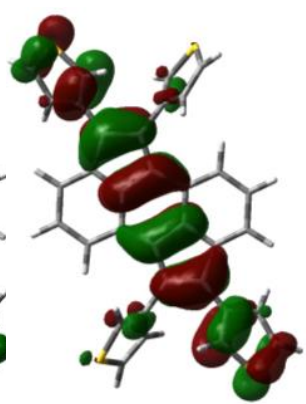

11(-5.2896)
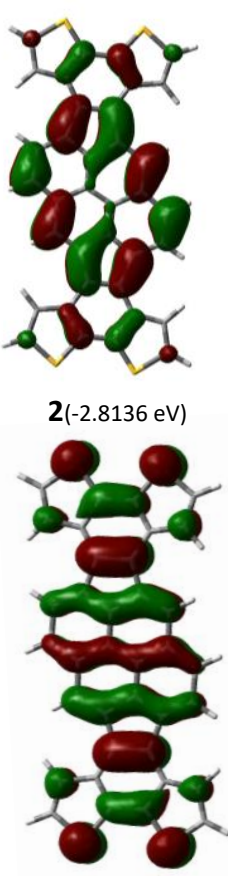

2(-5.4844 eV)

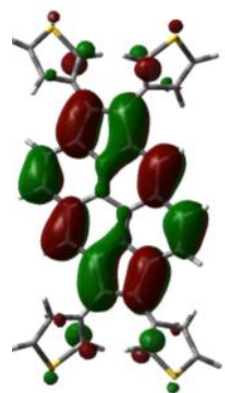

12(-2.9404 eV)

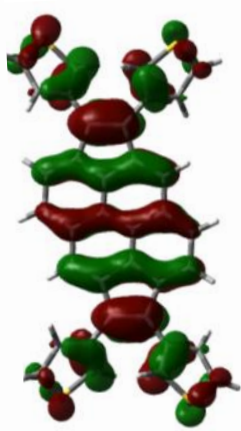

12(5.3005 eV)
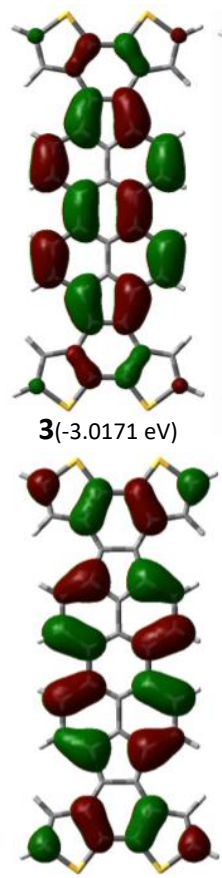

3(-5.4176 eV)

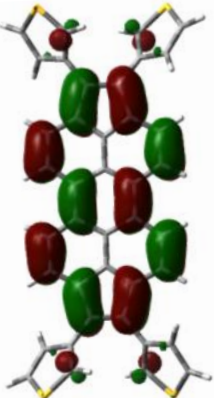

13(-3.1219 eV)

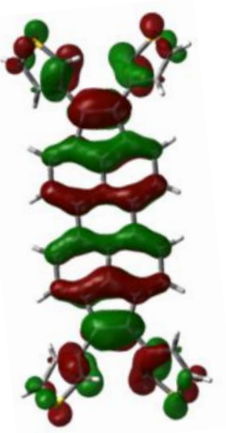

13(-5.3176 eV)

Figure 5 . HOMO (bottom) and LUMO (top) contours of 1-3 and 11-13 with B3LYP/6-311g(d,p) DFT calculated energy values, respectively. The alkyl chains were replaced with hydrogens for simplistic optimization.

region throughout the CP-PAH core and the flanked thiophene rings in a diagonal fashion, which is in agreement with previously difunctionalized cyclopenta[hi]aceanthrylenes. ${ }^{20,50}$ However, the thiophene rings orthogonal to the major diagonal delocalization path possess very little electron density in 11. The delocalization distribution between $\mathbf{2}$ and $\mathbf{1 2}$ as well as $\mathbf{3}$ and $\mathbf{1 3}$ were more similar owing to the more symmetric arrangement of the thiophene appendages. While the HOMO levels were significantly distributed across the whole molecule, the LUMOs in all compounds reside significantly more at the inner core, which is responsible for the cyclopentadienyl anion character. 
Table 1. Summary of optical and electronic properties of 1-3 and 11-13*

\begin{tabular}{|c|c|c|c|c|c|c|c|c|c|}
\hline Compound & $\boldsymbol{E}_{\text {ox/onset }}$ & $\boldsymbol{E}_{\text {red/onset }}$ & \multicolumn{2}{c|}{ HOMO(eV) } & \multicolumn{2}{c|}{ LUMO(eV) } & \multicolumn{2}{c|}{ E-chem gap(eV) } & Optical \\
& $(\mathbf{V})$ & (V) & Exp. & Calc. & Exp. & Calc. & Exp. & Calc. & gap (eV) \\
\hline $\mathbf{1}$ & 0.25 & -1.47 & -5.05 & -5.39 & -3.33 & -2.97 & 1.72 & 2.42 & 1.66 \\
\hline $\mathbf{2}$ & 0.48 & -1.66 & -5.28 & -5.48 & -3.14 & -2.81 & 2.14 & 2.67 & 2.14 \\
\hline $\mathbf{3}$ & 0.68 & -1.38 & -5.48 & -5.41 & -3.42 & -3.01 & 2.06 & 2.40 & 1.79 \\
\hline $\mathbf{1 1}$ & 0.42 & -1.41 & -5.22 & -5.28 & -3.39 & -3.02 & 1.83 & 2.26 & 1.48 \\
\hline $\mathbf{1 2}$ & 0.46 & -1.47 & -5.26 & -5.30 & -3.34 & -2.94 & 1.93 & 2.36 & 2.00 \\
\hline $\mathbf{1 3}$ & 0.39 & -1.32 & -5.19 & -5.31 & -3.48 & -3.12 & 1.71 & 2.19 & 2.02 \\
\hline
\end{tabular}

"Measurements taken at sample concentration of $0.2 \mathrm{mM}$ and potentials measured relative to ferrocenium/ferrocene redox couple used as an internal standard (Figure 4 ). $E_{\text {ox/onset }}$ is the onset of oxidation potential, $E_{\text {red/onset }}$ is the onset of reduction potential. HOMO and LUMO values calculated on the basis of oxidation of ferrocene referenced in vacuum $(4.8 \mathrm{eV})$. DFT predicted values are shown in columns parallel to the experimental ones and calculated on the basis of hydrogen side chain derivatives. Optical gap measured from film-based diffused reflectance spectra (ESI).

Organic field effect transistors in bottom gate bottom contact mode were fabricated on silicon wafers. All newly synthesized CP-PAHs 1-3 were tested for their semiconducting -properties and were found to be operating in a p-type regime with compound 1 giving an average hole mobility of $3.39 \times 10^{-4}$ $\mathrm{cm}^{2} \mathrm{~V}^{-1} \mathrm{~s}^{-1} \pm 1.77 \times 10^{-4}$ (Figure 5 and 6). Significantly smaller mobilities were found for the other compounds and were judged to not be significant. The poor performances of $\mathbf{2 - 3}$ was attributed to the poor film formation owing to their strong aggregation and very low solubilities.

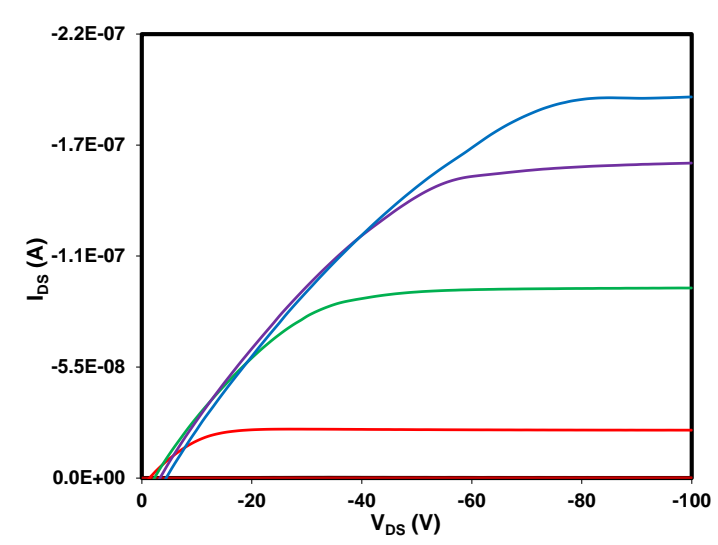

Figure 5. Typical output curves for 1 showing ptype semiconducting behavior.

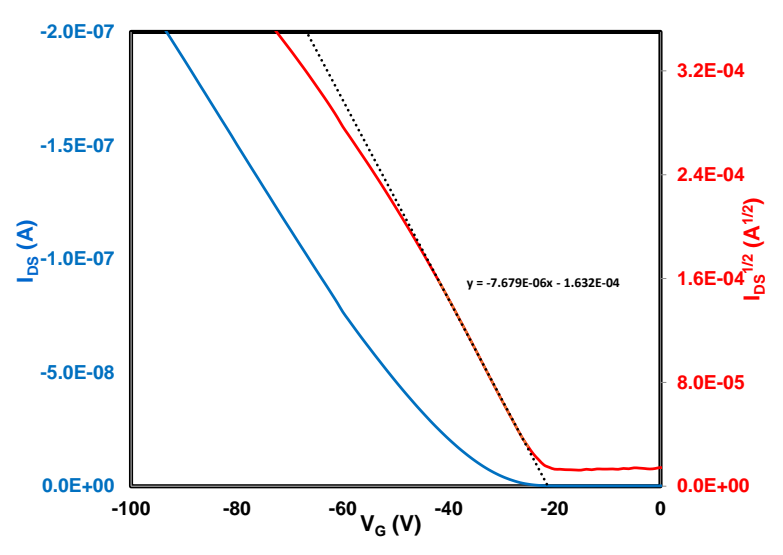

Figure 6. Typical transfer curve for p-type semiconductor 1 with average hole mobility of $3.39 \mathrm{X}$ $10^{-04} \mathrm{~cm}^{2} \mathrm{~V}^{-1} \mathrm{~s}^{-1}$.

In conclusion, we have prepared a new class of CP-PAHs with benzodithiophene appendages. The dibromoderivatives of anthracene, pyrene and perylene undergo a facile metal-catalyzed cyclopentannulation reaction with 1,2-bis(5-hexylthiophen-3-yl)ethyne that can be further transformed 
utilizing a Scholl cyclodehydrogenation. These newly synthesized CP-PAHs gave broad absorption and reasonably low LUMOs and adopted contorted structures when possessing [5]helicene-like arrangements of aromatic groups.

\section{Experimental Section}

General Procedures. Unless otherwise noted, all reagents were used as received and all reactions were carried out under an argon atmosphere. ${ }^{1} \mathrm{H}$ NMR and ${ }^{13} \mathrm{C}$ NMR were recorded on a $400 \mathrm{MHz}$ NMR station at room temperature, unless otherwise noted.

1,2-bis(5-hexylthiophen-3-yl)ethyne 10: In a glove box, 4-bromo-2-hexylthiophene (0.84 g, $3.40 \mathrm{mmol})$, $\mathrm{PdCl}_{2}\left(\mathrm{PPh}_{3}\right)_{2}(0.14 \mathrm{~g}, 0.020 \mathrm{mmol}), \mathrm{DBU}(6.59 \mathrm{~mL}, 44.21 \mathrm{mmol})$ and $\mathrm{CuI}(0.06 \mathrm{~g}, 0.03 \mathrm{mmol})$ were dissolved in toluene $(15 \mathrm{~mL})$ in a sealed tube. Argon purged $\mathrm{H}_{2} \mathrm{O}(0.10 \mathrm{ml}, 2.30 \mathrm{mmol})$ and trimethylsilyl acetylene $(0.29 \mathrm{~mL}, 2.04 \mathrm{mmol})$ were added to the sealed tube outside the glove box in the presence of argon. The tube was re-sealed and reaction mixture was stirred at $80{ }^{\circ} \mathrm{C}$ overnight. The reaction mixture was cooled to room temperature, acidified with $2 \mathrm{~N} \mathrm{HCl}$, and then extracted with diethyl ether ( $3 \mathrm{X} 120$ $\mathrm{mL})$. The organic layer was washed with $1 \mathrm{~N} \mathrm{HCl}(2 \times 100 \mathrm{ml})$, brine $(1 \times 100 \mathrm{~mL})$ and dried over $\mathrm{MgSO}_{4}$. The crude product was purified by column chromatography (100\% hexane, $\mathrm{R}_{\mathrm{f}}=0.4$ with $100 \%$ hexane) to obtain $10(60 \%)$ as a colorless viscous liquid. ${ }^{1} \mathrm{H}$ NMR $\left(400 \mathrm{MHz}, \mathrm{CD}_{2} \mathrm{Cl}_{2}\right) \delta 7.28(\mathrm{~d}, J=1.3 \mathrm{~Hz}, 2 \mathrm{H}), 6.85$ $(\mathrm{dd}, J=2.3,1.0 \mathrm{~Hz}, 2 \mathrm{H}), 2.93-2.64(\mathrm{t}, 4 \mathrm{H}), 1.68(\mathrm{~m}, J=22.5,7.4 \mathrm{~Hz}, 4 \mathrm{H}), 1.35(\mathrm{~m}, J=15.8,6.9 \mathrm{~Hz}$, $12 \mathrm{H}), 0.90(\mathrm{t}, J=7.1 \mathrm{~Hz}, 6 \mathrm{H}) .{ }^{13} \mathrm{C}\{1 \mathrm{H}\} \mathrm{NMR}\left(101 \mathrm{MHz}, \mathrm{CD}_{2} \mathrm{Cl}_{2}\right) \delta 146.1(\mathrm{~s}), 126.4(\mathrm{~s}), 126.1(\mathrm{~s}), 121.5$ (s), 83.7 (s), 31.5 (s), 31.4 (s), 29.8 (s), 28.7 (s), 22.5 (s), 13.8 (s). LRMS (TOFEI ${ }^{+}$) 358.2, HRMS: (TOFEI $\left.{ }^{+}\right)$ $\mathrm{m} / \mathrm{z}$ for $\mathrm{C}_{22} \mathrm{H}_{30} \mathrm{~S}_{2}$ calc: 358.1789 , found 358.1718 .

4,4',4",4"'-(cyclopenta[hi]aceanthrylene-1,2,6,7-tetrayl)tetrakis(2-hexylthiophene) 11: In a glove box, 1,2bis(5-hexylthiophen-3-yl)ethyne (178 mg, $0.49 \mathrm{mmol})$, 9,10-dibromoanthracene ( $80 \mathrm{mg}, 0.23 \mathrm{mmol}$ ), $\mathrm{Pd}_{2}(\mathrm{dba})_{3}(43.0 \mathrm{mg}, 0.04 \mathrm{mmol}), \mathrm{P}(\mathrm{o}-\mathrm{Tol})_{3}(18.1 \mathrm{mg}, 0.05 \mathrm{mmol}), \mathrm{KOAc}(116 \mathrm{mg}, 1.19 \mathrm{mmol}), \mathrm{LiCl}(20.2$ $\mathrm{mg}, 0.47 \mathrm{mmol})$, and DMF:Tol $(1: 1,8 \mathrm{~mL})$ were combined in a sealed tube and stirred overnight at $110{ }^{\circ} \mathrm{C}$ in the absence of light. The reaction mixture was cooled to room temperature and concentrated on rotavap and poured dropwise into ice cold methanol $(50 \mathrm{~mL})$ and filtered. The solid was washed with methanol and purified with silica gel chromatography (95\% Hexane: $5 \% \mathrm{CH}_{2} \mathrm{Cl}_{2}, \mathrm{R}_{\mathrm{f}}=0.3$ with 19:1 hexane: $\mathrm{CH}_{2} \mathrm{Cl}_{2}$ ) to give $50.2 \mathrm{mg}$ (39\%) of 11 as a green solid. ${ }^{1} \mathrm{H}$ NMR (400 MHz, $\left.\mathrm{CD}_{2} \mathrm{Cl}_{2}\right) \delta 7.91(\mathrm{~d}, J=6.6 \mathrm{~Hz}, 2 \mathrm{H}), 7.81$ $(\mathrm{d}, J=8.6 \mathrm{~Hz}, 2 \mathrm{H}), 7.48(\mathrm{dd}, J=8.6,6.7 \mathrm{~Hz}, 2 \mathrm{H}), 7.19(\mathrm{dd}, J=4.1,1.4 \mathrm{~Hz}, 4 \mathrm{H}), 6.98(\mathrm{~d}, 2 \mathrm{H}), 6.76(\mathrm{~d}, J=$ $1.1 \mathrm{~Hz}, 2 \mathrm{H}), 2.95$ (t, $J=7.4 \mathrm{~Hz}, 4 \mathrm{H}), 2.78$ (t, $J=7.5 \mathrm{~Hz}, 4 \mathrm{H}), 1.79(\mathrm{~m}, J=15.2,7.6 \mathrm{~Hz}, 6 \mathrm{H}), 1.72-1.60$ $(\mathrm{m}, 6 \mathrm{H}), 1.51-1.32(\mathrm{~m}, 20 \mathrm{H}), 0.99-0.89(\mathrm{~m}, 12 \mathrm{H}) .{ }^{13} \mathrm{C}\{1 \mathrm{H}\} \mathrm{NMR}\left(101 \mathrm{MHz}, \mathrm{CD}_{2} \mathrm{Cl}_{2}\right) \delta 146.2,145.3$, $140.3,138.0,136.8,135.4,134.1,134.0,128.4,127.7,127.1,125.9,125.7,125.6,124.7,122.1,121.3$, 31.9, 31.6, 31.5, 30.0, 20.0, 28.8, 28.7, 22.7, 22.6, 13.9. LRMS $\left(\mathrm{ES}^{+}\right)$890.40, HRMS: $\left(\mathrm{EI}^{+}\right) \mathrm{m} / \mathrm{z}$ for $\mathrm{C}_{58} \mathrm{H}_{66} \mathrm{~S}_{4}$ calc: 890.4047 , found 890.4042 .

2,5,11,14-tetrahexylrubiceno[5,4-b:6,7-b':12,11- $\left.b^{\prime \prime}: 13,14-b^{\prime \prime \prime}\right]$ tetrathiophene 1: In a round bottom flask, 11 (80 mg, $0.089 \mathrm{mmol}$ ) was dissolved in $70 \mathrm{ml}$ of $\mathrm{CH}_{2} \mathrm{Cl}_{2}$ and purged with argon for 30 minutes. To this mixture $\mathrm{FeCl}_{3}(87 \mathrm{mg}, 0.53 \mathrm{mmol})$ in $7 \mathrm{ml}$ of argon purged $\mathrm{CH}_{3} \mathrm{NO}_{2}$ was added drop wise in a glove box. The reaction mixture was stirred at room temperature overnight inside the glove box. The solvent was reduced to $5 \mathrm{~mL}$ by rotovap and ice-cold methanol $(30 \mathrm{ml})$ was added, and the mixture was stirred for 20 $\mathrm{min}$. The product was collected by filtration and washed with methanol. The collected solid was subjected to silica gel chromatography (gradient $0 \rightarrow 20 \% \mathrm{CH}_{2} \mathrm{Cl}_{2}$ in hexane, $\mathrm{R}_{\mathrm{f}}=0.2$ in 4:1 hexane: $\mathrm{CH}_{2} \mathrm{Cl}_{2}$ ) to give $70 \mathrm{mg}(88 \%)$ of 1 as an amethyst solid. ${ }^{1} \mathrm{H}$ NMR $\left(400 \mathrm{MHz}, \mathrm{CD}_{2} \mathrm{Cl}_{2}\right) \delta 8.01(\mathrm{~d}, J=8.8 \mathrm{~Hz}, 2 \mathrm{H}), 7.43(\mathrm{~d}, J$ $=6.6 \mathrm{~Hz}, 2 \mathrm{H}), 7.33(\mathrm{~s}, 2 \mathrm{H}), 7.04(\mathrm{dd}, J=7.6 \mathrm{~Hz}, 2 \mathrm{H}), 6.94(\mathrm{~s}, 2 \mathrm{H}), 2.47(\mathrm{t}, J=7.4 \mathrm{~Hz}, 4 \mathrm{H}), 2.41(\mathrm{t}, J=7.6$ 
$\mathrm{Hz}, 4 \mathrm{H}), 1.28(\mathrm{tt}, J=15.0,7.5 \mathrm{~Hz}, 8 \mathrm{H}), 1.01-0.87(\mathrm{~m}, 8 \mathrm{H}), 0.81(\mathrm{~m}, 8 \mathrm{H}), 0.66(\mathrm{~s}, 8 \mathrm{H}), 0.35(\mathrm{~m}, 12 \mathrm{H})$. ${ }^{13} \mathrm{C}\{1 \mathrm{H}\}$ NMR $\left(101 \mathrm{MHz}, \mathrm{CD}_{2} \mathrm{Cl}_{2}\right) \delta 146.6,145.0,137.7,135.9,133.2,132.8,132.3,131.8,130.6,129.7$, 127.5, 125.3, 124.1, 121.8, 118.1, 31.0, 30.6, 30.5, 29.1, 28.3, 22.0, 22.0, 13.5. LRMS (EI+) 886.3, HRMS: $\left(\mathrm{ASAP}^{+}\right) \mathrm{m} / \mathrm{z}$ for $\mathrm{C}_{58} \mathrm{H}_{62} \mathrm{~S}_{4}$ calc: 886.3734 , found 886.3729 .

4,4',4",4"'-(dicyclopenta[cd,jk]pyrene-1,2,6,7-tetrayl)tetrakis(2-hexylthiophene) 12: In a glove box, 1,2bis(5-hexylthiophen-3-yl)ethyne (84 mg, $2.34 \mathrm{mmol})$, 9,10-dibromoanthracene (40.0 mg, $1.11 \mathrm{mmol})$, $\mathrm{Pd}_{2}(\mathrm{dba})_{3}(60.0 \mathrm{mg}, 0.04 \mathrm{mmol}), \mathrm{P}(\mathrm{o}-\mathrm{Tol})_{3}(18.1 \mathrm{mg}, 0.05 \mathrm{mmol}), \mathrm{KOAc}(116 \mathrm{mg}, 1.19 \mathrm{mmol}), \mathrm{LiCl}(20.2$ $\mathrm{mg}, 0.22 \mathrm{mmol})$, and DMF:Tol (1:1) $8 \mathrm{~mL}$ were combined in a sealed tube and stirred overnight at $110^{\circ} \mathrm{C}$ in the absence of light. The reaction mixture was cooled to room temperature and poured in water $(200 \mathrm{~mL})$ and extracted with dichloromethane $(3 \times 30 \mathrm{~mL})$. The combined organic phases were dried over sodium sulphate and concentrated on rotavap until a small volume of solvent was left inside. The contents of flask were added dropwise into ice cold methanol $50 \mathrm{ml}$ and filtered. The solid was washed with methanol and purified with silica gel chromatography (95\% Hexane: $5 \% \mathrm{CH}_{2} \mathrm{Cl}_{2}, \mathrm{R}_{\mathrm{f}}=0.2$ in 19:1 hexane: $\mathrm{CH}_{2} \mathrm{Cl}_{2}$ ). The purified product was collected as tuscan solid in $85 \%$ yield. ${ }^{1} \mathrm{H} \mathrm{NMR}\left(400 \mathrm{MHz}, \mathrm{CD}_{2} \mathrm{Cl}_{2}\right) \delta 7.74(\mathrm{~d}, J=7.8$ $\mathrm{Hz}, 2 \mathrm{H}), 7.59(\mathrm{~d}, J=8.3 \mathrm{~Hz}, 4 \mathrm{H}), 7.30(\mathrm{~d}, J=1.4 \mathrm{~Hz}, 2 \mathrm{H}), 7.24(\mathrm{~d}, J=1.4 \mathrm{~Hz}, 2 \mathrm{H}), 6.81-6.76(\mathrm{~m}, 4 \mathrm{H})$, $2.82(\mathrm{~m}, J=17.3,7.6 \mathrm{~Hz}, 8 \mathrm{H}), 1.86-1.58(\mathrm{~m}, 12 \mathrm{H}), 1.40-1.31(\mathrm{~m}, 20 \mathrm{H}), 0.92(\mathrm{td}, J=6.9,1.9 \mathrm{~Hz}, 12 \mathrm{H})$. ${ }^{13} \mathrm{C}\{1 \mathrm{H}\}$ NMR $\left(101 \mathrm{MHz}, \mathrm{CD}_{2} \mathrm{Cl}_{2}\right) \delta 145.6,145.5,144.6,141.3,140.6,136.3,135.3,135.1,131.9,130.1$, 129.4, 125.6, 125.2, 124.7, 121.7, 121.6, 121.5, 121.1, 31.7, 31.7, 31.6, 30.0, 29.7, 28.8, 22.6, 13.8. LRMS (EI $\left.{ }^{+}\right)$914.6, HRMS: $\left(\mathrm{EI}^{+}\right) \mathrm{m} / \mathrm{z}$ for $\mathrm{C}_{60} \mathrm{H}_{66} \mathrm{~S}_{4}$ calc: 914.4047 , found 914.4081 .

2,5,11,14-tetrahexyldithieno-[4,5:6,7]indeno[1,2,3-cd]dithieno[4,5:6,7]indeno-[1,2,3-jk]pyrenes 2: In a round bottom flask $12(50 \mathrm{mg}, 0.054 \mathrm{mmol})$ was dissolved in $60 \mathrm{ml}$ of $\mathrm{CH}_{2} \mathrm{Cl}_{2}$ and purged with argon for 30 minutes in ice bath. To this mixture $\mathrm{FeCl}_{3}(35 \mathrm{mg}, 0.21 \mathrm{mmol})$ in $6 \mathrm{~mL}$ of $\mathrm{CH}_{3} \mathrm{NO}_{2}$ was added drop wise in a glove box. The reaction mixture was stirred at room temperature overnight inside the glove box. The solvent was reduced to $3 \mathrm{~mL}$ by rotovap and ice-cold methanol $(30 \mathrm{ml})$ was added, and the mixture was stirred for $20 \mathrm{~min}$. The product was collected by filtration and washed with methanol. The collected solid was subjected to recrystallization in 5\% DCM:Hexane to give $34 \mathrm{mg}(87 \%)$ of 2 as a melon red solid. ${ }^{1} \mathrm{H}$ NMR $\left(400 \mathrm{MHz}, \mathrm{CD}_{2} \mathrm{Cl}_{2}\right) \delta 7.88(\mathrm{~d}, J=16.5 \mathrm{~Hz}, 6 \mathrm{H}), 7.40(\mathrm{~d}, J=12.8 \mathrm{~Hz}, 4 \mathrm{H}), 3.00-2.84$ (t, $8 \mathrm{H}), 1.88-1.72(\mathrm{~m}, 8 \mathrm{H}), 1.52-1.41(\mathrm{~m}, 10 \mathrm{H}), 1.34(\mathrm{~s}, 12 \mathrm{H}), 1.20(\mathrm{~s}, 2 \mathrm{H}), 0.89$ (dd, $J=10.5,6.5 \mathrm{~Hz}$, 12H). Too insoluble for ${ }^{13} \mathrm{C}$ NMR. LRMS (EI $\left.{ }^{+}\right)$910.3, HRMS: $\left(\mathrm{ASAP}^{+}\right) \mathrm{m} / \mathrm{z}$ for $\mathrm{C}_{60} \mathrm{H}_{62} \mathrm{~S}_{4}$ calc: 910.3734 , found 910.3729 .

1,2,7,8-tetrakis(5-hexylthiophen-3-yl)dicyclopenta[cd,lm]perylene 13: In a glove box, 1,2-bis(5hexylthiophen-3-yl)ethyne (77 mg, $0.216 \mathrm{mmol}), 3$,9-dibromoperylene (42.0 mg, $0.103 \mathrm{mmol}), \mathrm{Pd}_{2}(\mathrm{dba})_{3}$ (18. mg, $0.02 \mathrm{mmol}), \mathrm{P}(\mathrm{o}-\mathrm{Tol})_{3}(7 \mathrm{mg}, 0.025 \mathrm{mmol}), \mathrm{KOAc}$ (50 mg, $\left.0.51 \mathrm{mmol}\right), \mathrm{LiCl}(8 \mathrm{mg}, 0.20 \mathrm{mmol})$, and DMF:Tol (1:1) $8 \mathrm{~mL}$ were combined in a sealed tube and stirred overnight at $110{ }^{\circ} \mathrm{C}$ in the absence of light. The reaction mixture was cooled to room temperature and poured in water $(200 \mathrm{~mL})$ and extracted with dichloromethane $(3 \times 30 \mathrm{~mL})$. The combined organic phases were dried over sodium sulphate and concentrated on rotavap until a small volume of solvent was left inside. Poured the contents of flask dropwise into ice cold methanol $50 \mathrm{ml}$ and filtered. The solid was washed with methanol and purified with silica gel chromatography with (95\% Hexane: $5 \% \mathrm{CH}_{2} \mathrm{Cl}_{2}, \mathrm{R}_{\mathrm{f}}=0.2$ in 19:1 hexane: $\mathrm{CH}_{2} \mathrm{Cl}_{2}$ ). The purified product was collected as magenta solid in $65 \%$ yield. ${ }^{1} \mathrm{H} \mathrm{NMR}\left(400 \mathrm{MHz}, \mathrm{CD}_{2} \mathrm{Cl}_{2}\right) \delta 7.87(\mathrm{~d}, J=7.6 \mathrm{~Hz}$, $4 \mathrm{H}), 7.49(\mathrm{~d}, J=7.5 \mathrm{~Hz}, 4 \mathrm{H}), 7.20(\mathrm{~d}, J=1.4 \mathrm{~Hz}, 4 \mathrm{H}), 6.77(\mathrm{~d}, J=1.1 \mathrm{~Hz}, 4 \mathrm{H}), 2.82(\mathrm{t}, J=7.4 \mathrm{~Hz}, 8 \mathrm{H})$, $1.75-1.64(\mathrm{~m}, 16 \mathrm{H}), 1.45-1.26(\mathrm{~m}, 20 \mathrm{H}), 0.93(\mathrm{t}, J=6.9 \mathrm{~Hz}, 12 \mathrm{H}) .{ }^{13} \mathrm{C}\{1 \mathrm{H}\} \mathrm{NMR}\left(101 \mathrm{MHz}, \mathrm{CD}_{2} \mathrm{Cl}_{2}\right)$ $\delta 145.5,140.9,135.2,132.9,131.0,130.1,125.6,124.2,122.2,121.4,31.7,31.6,30.0,28.8,22.6,13.9$. LRMS (EI') 964.3, HRMS: (ASAP ${ }^{+}$) m/z for $\mathrm{C}_{64} \mathrm{H}_{68} \mathrm{~S}_{4}$ calc: 964.4204 , found 964.4198. 
2,9,12,19-tetrahexyldithieno[4,5:6,7]indaceno[1,2,3-cd]dithieno[4,5:6,7]indaceno[1,2,3-lm]perylene 3: In a round bottom flask 13 (40 mg, $0.060 \mathrm{mmol}$ ) was dissolved in $60 \mathrm{~mL}$ of $\mathrm{CH}_{2} \mathrm{Cl}_{2}$ and purged with argon for 30 minutes. To this mixture $\mathrm{FeCl}_{3}(58 \mathrm{mg}, 0.36 \mathrm{mmol})$ in $6 \mathrm{ml}$ of $\mathrm{CH}_{3} \mathrm{NO}_{2}$ was added drop wise in a glove box. The reaction mixture was stirred at room temperature overnight inside the glove box. The solvent was reduced to $5 \mathrm{~mL}$ by rotovap and ice-cold methanol $(30 \mathrm{ml})$ was added, and the mixture was stirred for $20 \mathrm{~min}$. The product was collected by filtration and washed with methanol. The collected solid was subjected silica gel chromatography $\left(5 \% \mathrm{CH}_{2} \mathrm{Cl}_{2}\right.$ : $95 \%$ Hexane) to give $33 \mathrm{mg}(84 \%)$ of $\mathbf{3}$ as an orchid colored solid. ${ }^{1} \mathrm{H}$ NMR $\left(400 \mathrm{MHz}, \mathrm{CD}_{2} \mathrm{Cl}_{2}\right) \delta 7.45(\mathrm{~d}, 4 \mathrm{H}), 7.28(\mathrm{~d}, J=6.5 \mathrm{~Hz}, 4 \mathrm{H}), 6.86(\mathrm{~s}, 4 \mathrm{H}), 2.39(\mathrm{t}$, $J=7.3 \mathrm{~Hz}, 8 \mathrm{H}), 1.25(\mathrm{dt}, J=14.9,7.5 \mathrm{~Hz}, 8 \mathrm{H}), 0.94-0.88(\mathrm{~m}, 8 \mathrm{H}), 0.81-0.78(\mathrm{~m}, 4 \mathrm{H}), 0.66(\mathrm{~s}, 4 \mathrm{H}), 0.34$ $(\mathrm{t}, J=6.9 \mathrm{~Hz}, 12 \mathrm{H}), 0.26(\mathrm{~d}, J=6.5 \mathrm{~Hz}, 4 \mathrm{H})$. Too insoluble for ${ }^{13} \mathrm{C}$ NMR. LRMS $\left(\mathrm{EI}^{+}\right)$960.3, HRMS: $\left(\mathrm{ASAP}^{+}\right) \mathrm{m} / \mathrm{z}$ for $\mathrm{C}_{64} \mathrm{H}_{64} \mathrm{~S}_{4}$ calc: 960.3891 , found 960.3885 .

\section{Associated Content}

The Supporting Information is available free of charge at XXX.

Figures of DFT energy minimized structures, molar absorptivity, diffusion reflectance, photo-oxidation profile, cyclic voltammetry, NMR spectra, and DFT tables.

\section{Acknowledgments}

This work was supported by a National Science Foundation CAREER grant (CHE-1352431). 


\section{References}

1. Gingras, M., One hundred years of helicene chemistry. Part 1: non-stereoselective syntheses of carbohelicenes. Chemical Society Reviews 2013, 42 (3), 968-1006.

2. Fukui, N.; Kim, T.; Kim, D.; Osuka, A., Porphyrin arch-tapes: synthesis, contorted structures, and full conjugation. Journal of the American Chemical Society 2017, 139 (26), 9075-9088.

3. Xiao, S.; Myers, M.; Miao, Q., S. b. Sanaur, K. Pang, ML Steigerwald and C. Nuckolls. Angew. Chem., Int. Ed 2005, 44, 7390-7394.

4. Chiu, C.-Y.; Kim, B.; Gorodetsky, A. A.; Sattler, W.; Wei, S.; Sattler, A.; Steigerwald, M.; Nuckolls, C., Shape-shifting in contorted dibenzotetrathienocoronenes. Chemical Science 2011, 2 (8), 1480-1486.

5. Arslan, H.; Uribe-Romo, F. J.; Smith, B. J.; Dichtel, W. R., Accessing extended and partially fused hexabenzocoronenes using a benzannulation-cyclodehydrogenation approach. Chemical Science 2013, 4 (10), 3973-3978.

6. Xiao, S.; Kang, S. J.; Wu, Y.; Ahn, S.; Kim, J. B.; Loo, Y.-L.; Siegrist, T.; Steigerwald, M. L.; Li, H.; Nuckolls, C., Supersized contorted aromatics. Chemical Science 2013, 4 (5), 2018-2023.

7. Zhong, Y.; Kumar, B.; Oh, S.; Trinh, M. T.; Wu, Y.; Elbert, K.; Li, P.; Zhu, X.; Xiao, S.; Ng, F., Helical ribbons for molecular electronics. Journal of the American Chemical Society 2014, 136 (22), 8122-8130.

8. Yang, X.; Liu, D.; Miao, Q., Heptagon-Embedded Pentacene: Synthesis, Structures, and Thin-Film Transistors of Dibenzo [d, d'] benzo [1, 2-a: 4, 5-a'] dicycloheptenes. Angewandte Chemie 2014, $126(26), 6904-6908$.

9. $\mathrm{Gu}, \mathrm{X} . ; \mathrm{Xu}, \mathrm{X}$.; Li, H.; Liu, Z.; Miao, Q., Synthesis, Molecular Packing, and Thin Film Transistors of Dibenzo [a, m] rubicenes. Journal of the American Chemical Society 2015, 137 (51), 1620316208.

10. Cheung, K. Y.; Xu, X.; Miao, Q., Aromatic saddles containing two heptagons. Journal of the American Chemical Society 2015, 137 (11), 3910-3914.

11. Ito, S.; Hiroto, S.; Lee, S.; Son, M.; Hisaki, I.; Yoshida, T.; Kim, D.; Kobayashi, N.; Shinokubo, H., Synthesis of highly twisted and fully $\pi$-conjugated porphyrinic oligomers. Journal of the American Chemical Society 2015, 137 (1), 142-145.

12. Fujikawa, T.; Segawa, Y.; Itami, K., Synthesis and structural features of quadruple helicenes: highly distorted $\pi$ systems enabled by accumulation of helical repulsions. Journal of the American Chemical Society 2016, 138 (10), 3587-3595.

13. Li, Y.; Jia, Z.; Xiao, S.; Liu, H.; Li, Y., A method for controlling the synthesis of stable twisted twodimensional conjugated molecules. Nature communications 2016, 7 (1), 1-11.

14. Liu, J.; Narita, A.; Osella, S.; Zhang, W.; Schollmeyer, D.; Beljonne, D.; Feng, X.; Müllen, K., Unexpected Scholl reaction of 6, 7, 13, 14-tetraarylbenzo [k] tetraphene: selective formation of five-membered rings in polycyclic aromatic hydrocarbons. Journal of the American Chemical Society 2016, 138 (8), 2602-2608.

15. Yang, W.; Longhi, G.; Abbate, S.; Lucotti, A.; Tommasini, M.; Villani, C.; Catalano, V. J.; Lykhin, A. O.; Varganov, S. A.; Chalifoux, W. A., Chiral peropyrene: synthesis, structure, and properties. Journal of the American Chemical Society 2017, 139 (37), 13102-13109.

16. Chalifoux, W. A., The Synthesis of Non-planar, Helically Coiled Graphene Nanoribbons. Angewandte Chemie International Edition 2017, 56 (28), 8048-8050.

17. Subramanian, S.; Park, S. K.; Parkin, S. R.; Podzorov, V.; Jackson, T. N.; Anthony, J. E., Chromophore fluorination enhances crystallization and stability of soluble anthradithiophene semiconductors. Journal of the American Chemical Society 2008, 130 (9), 2706-2707. 
18. Shinamura, S.; Sugimoto, R.; Yanai, N.; Takemura, N.; Kashiki, T.; Osaka, I.; Miyazaki, E.; Takimiya, K., Orthogonally functionalized naphthodithiophenes: selective protection and borylation. Organic letters 2012, 14 (18), 4718-4721.

19. Jin, T.; Zhao, J.; Asao, N.; Yamamoto, Y., Metal-Catalyzed Annulation Reactions for $\pi$-Conjugated Polycycles. Chemistry-A European Journal 2014, 20 (13), 3554-3576.

20. Bheemireddy, S. R.; Ubaldo, P. C.; Finke, A. D.; Wang, L.; Plunkett, K. N., Contorted aromatics via a palladium-catalyzed cyclopentannulation strategy. Journal of Materials Chemistry C 2016, 4 (18), 3963-3969.

21. Larock, R. C.; Tian, Q., Synthesis of 9-Alkylidene-9 H-fluorenes by a Novel, Palladium-Catalyzed Cascade Reaction of Aryl Halides and 1-Aryl-1-alkynes. The Journal of organic chemistry 2001, 66 (22), 7372-7379.

22. Wegner, H. A.; Scott, L. T.; De Meijere, A., A new Suzuki- Heck-Type coupling cascade: Indeno [1, $2,3]$-annelation of polycyclic aromatic hydrocarbons. The Journal of organic chemistry 2003, 68 (3), 883-887.

23. Wu, Y. T.; Huang, K. H.; Shin, C. C.; Wu, T. C., Palladium-Catalyzed Formation of Highly Substituted Naphthalenes from Arene and Alkyne Hydrocarbons. Chemistry-A European Journal 2008, 14 (22), 6697-6703.

24. Chen, T.-A.; Liu, R.-S., Synthesis of large polycyclic aromatic hydrocarbons from bis (biaryl) acetylenes: large planar PAHs with Low $\pi$-sextets. Organic letters 2011, 13 (17), 4644-4647.

25. Liu, E. C.; Chen, M. K.; Li, J. Y.; Wu, Y. T., Palladium-Catalyzed Annulation of 9Halophenanthrenes with Alkynes: Synthesis, Structural Analysis, and Properties of Acephenanthrylene-Based Derivatives. Chemistry-A European Journal 2015, 21 (12), 4755-4761.

26. Jakubec, M.; Storch, J., Recent advances in functionalizations of helicene backbone. The Journal of Organic Chemistry 2020, 85 (21), 13415-13428.

27. Nagao, I.; Shimizu, M.; Hiyama, T., 9-Stannafluorenes: 1, 4-Dimetal Equivalents for Aromatic Annulation by Double Cross-Coupling. Angewandte Chemie 2009, 121 (41), 7709-7712.

28. Shimizu, M.; Nagao, I.; Tomioka, Y.; Hiyama, T., Palladium-Catalyzed Annulation of vic-Bis (pinacolatoboryl) alkenes and-phenanthrenes with 2, 2'-Dibromobiaryls: Facile Synthesis of Functionalized Phenanthrenes and Dibenzo $[\mathrm{g}, \mathrm{p}]$ chrysenes. Angewandte Chemie International Edition 2008, 47 (42), 8096-8099.

29. Anthony, J. E., The larger acenes: versatile organic semiconductors. Angewandte Chemie International Edition 2008, 47 (3), 452-483.

30. Mei, J.; Diao, Y.; Appleton, A. L.; Fang, L.; Bao, Z., Integrated materials design of organic semiconductors for field-effect transistors. Journal of the American Chemical Society 2013, 135 (18), 6724-6746.

31. Coropceanu, V.; Cornil, J.; da Silva Filho, D. A.; Olivier, Y.; Silbey, R.; Brédas, J.-L., Charge transport in organic semiconductors. Chemical reviews 2007, 107 (4), 926-952.

32. Dang, H.; Levitus, M.; Garcia-Garibay, M. A., One step Pd (0)-catalyzed synthesis, X-ray analysis, and photophysical properties of cyclopent [hi] aceanthrylene: Fullerene-like properties in a nonalternant cyclopentafused aromatic hydrocarbon. Journal of the American Chemical Society 2002, 124 (1), 136-143.

33. Dang, H.; Garcia-Garibay, M. A., Palladium-catalyzed formation of aceanthrylenes: A simple method for peri-cyclopentenelation of aromatic compounds. Journal of the American Chemical Society 2001, 123 (2), 355-356.

34. Lütke Eversloh, C.; Avlasevich, Y.; Li, C.; Müllen, K., Palladium-Catalyzed Pentannulation of Polycyclic Aromatic Hydrocarbons. Chemistry-A European Journal 2011, 17 (45), 12756-12762. 
35. Bheemireddy, S. R.; Hautzinger, M. P.; Li, T.; Lee, B.; Plunkett, K. N., Conjugated ladder polymers by a cyclopentannulation polymerization. Journal of the American Chemical Society 2017, 139 (16), 5801-5807.

36. Wex, B.; Kaafarani, B. R.; Danilov, E. O.; Neckers, D. C., Altering the emission behavior with the turn of a thiophene ring: the photophysics of condensed ring systems of alternating benzenes and thiophenes. The Journal of Physical Chemistry A 2006, 110 (51), 13754-13758.

37. Park, J.-I.; Chung, J. W.; Kim, J.-Y.; Lee, J.; Jung, J. Y.; Koo, B.; Lee, B.-L.; Lee, S. W.; Jin, Y. W.; Lee, S. Y., Dibenzothiopheno [6, 5-b: 6', 5'-f] thieno [3, 2-b] thiophene (DBTTT): High-performance small-molecule organic semiconductor for field-effect transistors. Journal of the American Chemical Society 2015, 137 (38), 12175-12178.

38. Bown, M.; Dunn, C. J.; Forsyth, C. M.; Kemppinen, P.; Singh, T. B.; Skidmore, M. A.; Winzenberg, K. N., First Synthesis of Diindeno [1, 2-g: $1^{\prime}, 2^{\prime}$-s] rubicene Derivatives and their Evaluation as Semiconductors. Australian Journal of Chemistry 2012, 65 (2), 145-152.

39. Lee, H.; Zhang, Y.; Zhang, L.; Mirabito, T.; Burnett, E. K.; Trahan, S.; Mohebbi, A. R.; Mannsfeld, S. C.; Wudl, F.; Briseno, A. L., Rubicene: a molecular fragment of $C 70$ for use in organic field-effect transistors. Journal of Materials Chemistry C 2014, 2 (17), 3361-3366.

40. Mohebbi, A. R.; Wudl, F., Electron-Accepting Dithiarubicene (Emeraldicene) and Derivatives Prepared by Unprecedented Nucleophilic Hydrogen Substitution by Alkyllithium Reagents. Chemistry-A European Journal 2011, 17 (9), 2642-2646.

41. Cho, B. P.; Harvey, R. G., Polycyclic fluoranthene hydrocarbons. 2. A new general synthesis. The Journal of Organic Chemistry 1987, 52 (26), 5668-5678.

42. Rice, J. E.; Cai, Z. W., An intramolecular arene-triflate coupling reaction for the regiospecific synthesis of substituted benzofluoranthenes. The Journal of Organic Chemistry 1993, 58 (6), 1415-1424.

43. Belova, V.; Hinderhofer, A.; Zeiser, C.; Storzer, T.; Rozbořil, J.; Hagenlocher, J.; Novák, J. i.; Gerlach, A.; Scholz, R.; Schreiber, F., Structure-Dependent Charge Transfer in Molecular Perylene-Based Donor/Acceptor Systems and Role of Side Chains. The Journal of Physical Chemistry C 2020, 124 (21), 11639-11651.

44. Wirsing, S.; Hänsel, M.; Belova, V.; Schreiber, F.; Broch, K.; Engels, B.; Tegeder, P., Excited-state dynamics in perylene-based organic semiconductor thin films: Theory meets experiment. The Journal of Physical Chemistry C 2019, 123 (45), 27561-27572.

45. Wynberg, H.; Groen, M.; Schadenberg, H., Synthesis and resolution of some heterohelicenes. The Journal of Organic Chemistry 1971, 36 (19), 2797-2809.

46. Murata, M.; Sugano, Y.; Wakamiya, A.; Murata, Y., Electron-Deficient Tetrabenzo-Fused Pyracylene and Conversions into Curved and Planar $\pi$-Systems Having Distinct Emission Behaviors. Angewandte Chemie International Edition 2015, 54 (32), 9308-9312.

47. Heinrich, M. A.; Pflaum, J.; Tripathi, A. K.; Frey, W.; Steigerwald, M. L.; Siegrist, T., Enantiotropic polymorphism in di-indenoperylene. The Journal of Physical Chemistry C 2007, 111 (51), 1887818881.

48. Sonmez, G.; Shen, C. K.; Rubin, Y.; Wudl, F., A red, green, and blue (RGB) polymeric electrochromic device (PECD): the dawning of the PECD era. Angewandte Chemie 2004, 116 (12), 1524-1528.

49. Plunkett, K. N.; Godula, K.; Nuckolls, C.; Tremblay, N.; Whalley, A. C.; Xiao, S., Expeditious synthesis of contorted hexabenzocoronenes. Organic letters 2009, 11 (11), 2225-2228.

50. Wood, J. D.; Jellison, J. L.; Finke, A. D.; Wang, L.; Plunkett, K. N., Electron Acceptors Based on Functionalizable Cyclopenta [hi] aceanthrylenes and Dicyclopenta [de, $\mathrm{mn}$ ] tetracenes. Journal of the American Chemical Society 2012, 134 (38), 15783-15789. 
51. Jellison, J. L.; Lee, C. H.; Zhu, X.; Wood, J. D.; Plunkett, K. N., Electron Acceptors Based on an AllCarbon Donor-Acceptor Copolymer. Angewandte Chemie 2012, 124 (49), 12487-12490. 